\title{
MDM2 polymorphism associated with the development of cervical lesions in women infected with Human papillomavirus and using of oral contraceptives
}

\author{
Carolina MM Amaral ${ }^{1}$, Katerina Cetkovská2, Ana PAD Gurgel ${ }^{1}$, Marcus V Cardoso ${ }^{3}$, Bárbara S Chagas ${ }^{1}$, \\ Sérgio SL Paiva Júnior ${ }^{3}$, Rita de Cássia Pereira de Lima', Jacinto C Silva-Neto ${ }^{4}$, Luiz AF Silva ${ }^{5}$, Maria TC Muniz ${ }^{6}$, \\ Valdir Q Balbino ${ }^{3}$ and Antonio C Freitas ${ }^{1 *}$
}

\begin{abstract}
Background: The MDM2 gene is the major negative regulator of p53, a tumor suppressor protein. Single nucleotide polymorphism in promoter region of MDM2 gene leads to increased expression resulting in higher levels of MDM2 protein. This event increases the attenuation of the p53 pathway. Polymorphisms in this gene can interfere in the regulation of cellular proliferation. We evaluated whether MDM2 SNP309 (rs2278744) associated or not with the use of oral contraceptive can heighten susceptibility to development of cervical lesions in women HPV infected.

Methods: MDM2 SNP309 (rs2278744) was genotyped in a total of 287 patients using the PCR-RFLP technique. The results were analyzed by UNPHASED v.3.121 and SNPStats programs.

Results: The three groups (SIL, LSIL and HSIL) showed no significant differences in either genotype or allelic frequencies for MDM2 polymorphisms, except when HSIL was compared with LSIL ( $p=0.037 ; \mathrm{OR}=1.81$ ). Furthermore, in the analysis of contraceptives, a significant association was found between the use of contraceptives and the MDM2 variant in the development of high-grade cervical lesions for the TG genotype $(p=0.019 ; \mathrm{OR}=2.21)$ when HSIL was compared with control. When HSIL was compared with LSIL ( $p=0.006 ; \mathrm{OR}=2.27)$.

Conclusion: The results of this study suggest that MDM2 SNP309 might be a good marker for assessing the progression of LSIL to HSIL. In addition, they also show that oral contraceptives alone, did not have any effect on the progression or development of cervical lesions. However, they may act synergistically with MDM2 SNP309 (rs2278744) and HPV infection in the development of cervical lesions.
\end{abstract}

Keywords: MDM2, HPV, Oral contraceptives, Cervical cancer

\section{Background}

Cervical cancer is the third most frequent cancer and the second most common cause of death among women worldwide [1]. Its prevalence is especially high in developing countries, which account for $86 \%$ of all cases [1]. In Brazil, there are more than 17,500 new cases every year and 4,812 deaths [2]. Currently, the main screening method for cervical cancer is the Papanicolau (Pap)

\footnotetext{
* Correspondence: acf_ufpe@yahoo.com.br

'Laboratory of Molecular Studies and Experimental Therapy, Department of Genetics, Universidade Federal de Pernambuco, Pernambuco, Brazil Full list of author information is available at the end of the article
}

smear test which is based on an analysis of cervical cell morphology. The cervical cancer precursor is the squamous intraepithelial lesion (SIL) that may be either a high squamous intraepithelial lesion (HSIL) or a low squamous intraepithelial lesion (LSIL) [3].

It is well established that the major etiological factor in cervical cancer is Human papillomavirus (HPV) infection [4,5]. HPV DNA is detected in over $95 \%$ of the cases of invasive cervical cancer worldwide [6]; however, the type of HPV, as well as genetic and environmental factors, can influence the persistence of HPV infection and the progression of lesions to cervical cancer [7-9]. The use 
of oral contraceptives has been put forward as a cofactor in the development of cervical cancer and in making the user predisposed to the disease [9]. It is believed that steroids hormones interact with a specific DNA sequences on transcriptional regulatory sites on the HPV DNA increasing or suppressing the transcription of various genes [10]. Estradiol and progesterone can be responsible for modulation the host genes that are involved in immune response to HPV16 [11]. Moreover, the association with cervical cancer depends the typespecific HPV infection [12]. The effects of oral contraceptive on cervical cancer are transient because the association increases with duration of use $[13,14]$ and decreases after discontinuation $[11,13,14]$.

The HPV E6 oncoprotein that is involved in cervical cancer makes use of the cellular ubiquitin-protein ligase E6-AP to target the p53 transcription factor for degradation [15]. The human homolog of mouse double minute $2(\mathrm{mdm} 2)$ protein is the main negative regulator of the p53 function [16]. Mdm2 targets the p53 protein by ubiquitination for its degradation and suppresses p53 by inhibiting its trans-activation function [17]. The level of p53 is regulated through an auto-regulatory feedback loop where 553 induces the transcription of MDM2.

The MDM2 regulation of disorders is associated with the development of cancer, which is confirmed by the evidence that $M D M 2$ was over-expressed in some human cancers [18,19]. MDM2 single nucleotide polymorphism SNP ( $r$ 2279744) has already been described as being associated with several types of cancer [20,21], and also with accelerated tumorigenesis and poor prognosis [22]. This polymorphism is located in position 309 in the first intron of the $M D M 2$ oncogene, which serves as a transcriptional enhancer region. When $\mathrm{T}$ is replaced with G, this increases the affinity of the Sp1 transcription factor and it has been shown that cells carrying the T309G genotype have a 2-3-fold increase in MDM2 mRNA and protein synthesis. This leads to the abrogation of p53 tumor suppressor activity and the development of cancer [23].

Our study sought to determine whether the presence of polymorphism in the $M D M 2$ gene associated or not with the use of oral contraceptives can heighten susceptibility to the development of cervical lesions in women HPV infected.

\section{Results}

This study was conducted with 212 cases of cervical lesions from North-East Brazil who underwent cervical cancer screening and 75 individuals that does not have lesions acting as a control group.

The age of the patients included in the current study ranged from 15-77 the average age being 33 and the mean was at $34.02+11.05$ years. In accordance with their
HPV types, $78 \%$ of all the patients were infected with high-risk HPV against 22\% that were infected with low-risk. In the control group, $65 \%$ were infected with high-risk HPV and 35\% with low-risk HPV. In the LSIL group, $74 \%$ were infected with high-risk HPV and 26\% with low-risk HPV. In the HSIL group, 98\% were infected with high-risk HPV and $2 \%$ with low-risk.

The SNP were evaluated in compliance with the HardyWeinberg principle. The frequencies of each allele and genotype are given in Table 1.

Patients with both LSIL and HSIL were included in the SIL group. The three groups (SIL, LSIL and HSIL) showed no significant differences in either genotype or allelic frequencies for MDM2 SNP309 polymorphism, except when HSIL was compared with LSIL for the MDM2 gene. The difference was significant $(\mathrm{p}=0.037 ; \mathrm{OR}=1.81$, 95\% CI 1.03-3.16) with regard to the TG genotype when TT was used as a reference-point. This showed that the significant genetic model was over-dominant, with the heterozygote being at a greater risk of evolution of LSIL for HSIL than either of the homozygotes. Although this is a no intuitive model, there is a precedent for other genes acting in this manner (see Discussion).

An examination was carried out to establish the possible influence of the use of hormonal contraceptives on the susceptibility of women to the development of cervical lesions (Table 2). There was no association between the use of contraceptives and LSIL and HSIL.

Another examination was carried out to establish the effects of the use of hormonal contraceptives (together with variants of the MDM2 gene) on the development of cervical lesions (Table 3). When the TT-GG genotypes were used as a reference-point, a significant difference was found between HSIL and the control groups $[p<0.05$; $\mathrm{OR}=2.21$ (1.13-4.30)] and the TG genotype, for MDM2 SNP309. A significant difference was also found in the TG genotype when HSIL was compared with LSIL. The risk ranged from 2.01 to 2.31 depending on the model used. For codominant model, the risk was 2.31; for dominant model, the risk was 2.01 and for overdominant model, the risk was 2.27 to TG genotype. Since the overdominant model was the most significant $(p=0.006)$. We also compared MDM2 SNP309 allele distribution among oral contraceptive users and non-users between the three groups, LSIL, HSIL and normal cytology (Table 4).

\section{Discussion}

In this study, we evaluated whether MDM2 SNP309 (rs2278744) associated or not with the use of oral contraceptive can heighten susceptibility to development of cervical lesions.

The nature of the relationship between MDM2 SNP309 (rs2278744) and cervical cancer is not clear. There have been few studies in this area and the conclusions are 
Table 1 MDM2 (rs2278744) polymorphism in patients with HPV and cervical lesions of low degree (LSIL) and high degree (HSIL) and healthy patients

\begin{tabular}{|c|c|c|c|c|c|c|c|c|}
\hline & \multicolumn{3}{|c|}{ Cases } & \multirow{2}{*}{$\begin{array}{c}\text { Normal cytology } \\
\text { Control }^{\mathrm{d}}\end{array}$} & \multicolumn{4}{|c|}{$p$-value; OR [95\% C.I.] } \\
\hline & Total SIL ${ }^{a}$ & LSIL $^{b}$ & $\mathrm{HSIL}^{\mathrm{c}}$ & & Total SIL vs. C & LSIL vs. C & HSIL vs. C & $\overline{\text { HSIL vs. LSIL }}$ \\
\hline \multicolumn{9}{|c|}{ SNP309 rs2278744 } \\
\hline \multicolumn{9}{|c|}{ Alelles } \\
\hline $\mathrm{T}$ & $265(0.62)$ & $165(0.63)$ & $100(0.61)$ & $95(0.63)$ & Reference & Reference & Reference & Reference \\
\hline G & $156(0.38)$ & $95(0.37)$ & $61(0.39)$ & $55(0.37)$ & $\begin{array}{c}0.80 ; 1.04 \\
{[0.71-1.54]}\end{array}$ & $\begin{array}{c}0.97 ; 0.99 \\
{[0.65-1.50]}\end{array}$ & $\begin{array}{c}0.67 ; 1.11 \\
{[0.70-1.75]}\end{array}$ & $\begin{array}{c}0.55 ; 1.14 \\
{[0.74-1.75]}\end{array}$ \\
\hline \multicolumn{9}{|c|}{ Genotypes } \\
\hline$\pi$ & $80(0.37)$ & $54(0.42)$ & $26(0.30)$ & $30(0.40)$ & Reference & Reference & Reference & Reference \\
\hline TG & $105(0.51)$ & $57(0.44)$ & $48(0.61)$ & $35(0.47)$ & $\begin{array}{c}0.83 ; 0.85 \\
{[0.48-1.49]}\end{array}$ & $\begin{array}{c}0.92 ; 1.11 \\
{[0.60-2.04]}\end{array}$ & $\begin{array}{c}0.33 ; 1.58 \\
{[0.80-3.13]}\end{array}$ & $\begin{array}{l}* 0.11 ; 1.75 \\
{[0.95-3.20]}\end{array}$ \\
\hline GG & $27(0.12)$ & $19(0.15)$ & $8(0.09)$ & $10(0.13)$ & $\begin{array}{c}0.83 ; 0.99 \\
{[0.43-2.28]}\end{array}$ & $\begin{array}{c}0.92 ; 0.95 \\
{[0.39-2.30]}\end{array}$ & $\begin{array}{c}0.33 ; 0.92 \\
{[0.32-2.69]}\end{array}$ & $\begin{array}{c}0.33 ; 0.92 \\
{[0.32-2.69]}\end{array}$ \\
\hline
\end{tabular}

$p<0.05$ - statistically significant.

${ }^{\mathrm{a} S I L}$ : Squamous intraepithelial lesions.

bLSIL: Low-grade squamous intraepithelial lesions.

${ }^{\mathrm{c} H S I L: ~ H i g h-g r a d e ~ s q u a m o u s ~ i n t r a e p i t h e l i a l ~ l e s i o n s . ~}$

${ }^{\mathrm{d} C} \mathrm{C}$ : Control - Normal cytology.

*In overdominant model the risk to TG genotype was $1.81(1.03-3.16,95 \% \mathrm{Cl})$

contradictory. We found that the differences in the frequency of MDM2 SNP309 (rs2278744) allele and genotype were not significant between the LSIL and HSIL groups, when compared with the control group. This is consistent with the results of a single study with a Brazilian population that was carried out to test whether MDM2 SNP309 (rs2278744) was associated with either the risk of cervical cancer or its diagnosis at an early age. In this study, Meissner et al. [24] compared 72 cervical carcinoma patients with 100 healthy patients and no association was observed between MDM2 SNP309 (rs2278744) and cervical cancer. Our results lend weight to the conclusions of Meissner et al. [24] that MDM2 SNP309 (rs2278744) may not be a risk factor for the development of cervical carcinogenesis.

However, our study found a statistically significant result of this SNP with the progression of LSIL to HSIL, which was not analyzed by Meissner et al. [24]. In contrast, recently, Singhal et al. [25] found association between higher frequency of $\mathrm{G}$ allele and cervical cancer in Indian women infected with HPV. In the study of a population in China, involving 167 cervical cancer and 223 controls, Jiang et al. [26] found an increased risk of cervical cancer associated with MDM2 SNP309 (rs2278744) GG. Nunobiki et al. [27] investigated whether or not the combination of MDM2 SNP309 (rs2278744) with HPV types could be associated with cervical lesions and cancer. Their study consisted of 102 LSIL, 41 HSIL and 52 normal (controls). MDM2 SNP309 (rs2278744) was found to be associated with cervical carcinogenesis especially in the high-risk HPV group.

The divergence between the findings of these studies and the present study might be caused by racial, ethnic or samples differences in the populations studied, since in our study we worked with pre-cancerous lesions. According to a study carried out by Wo et al. [28], in the case of an Asian population, the mean frequency of 309G is 0.49 and 0.36 for the mixed population. It

Table 2 Distribution of use of contraceptive according to the SIL, LSIL, HSIL and controls

\begin{tabular}{|c|c|c|c|c|c|c|c|c|}
\hline & \multicolumn{3}{|c|}{ Cases } & \multirow{2}{*}{$\begin{array}{l}\text { Normal cytology } \\
\text { Control }^{d}\end{array}$} & \multicolumn{4}{|c|}{$p$-value; OR [95\% C.I. $]$} \\
\hline & Total SIL ${ }^{\mathrm{a}}$ & LSIL $^{b}$ & $\mathrm{HSIL}^{\mathrm{c}}$ & & Total SIL vs. C & LSIL vs. C & HSIL vs. C & HSIL vs. LSIL \\
\hline \multicolumn{9}{|c|}{ Variable } \\
\hline \multicolumn{9}{|c|}{ Use of contraceptive } \\
\hline No & $167(0.68)$ & $109(0.65)$ & $58(0.75)$ & $55(0.68)$ & $\begin{array}{c}\mathrm{OR}=0.99 \\
{[0.55-1.79]}\end{array}$ & $\begin{array}{c}\mathrm{O}=1.14 \\
{[0.62-2.13]}\end{array}$ & $\begin{array}{c}\mathrm{OR}=0.69 \\
{[0.32-1.48]}\end{array}$ & $\begin{array}{c}\mathrm{OR}=0.60 \\
{[0.31-1.14]}\end{array}$ \\
\hline Yes & $78(0.32)$ & $95(0.35)$ & $19(0.25)$ & $25(0.32)$ & $p=1.0$ & $p=0.66$ & $p=0.37$ & $p=0.10$ \\
\hline
\end{tabular}

$p<0.05$ - statistically significant.

${ }^{\text {a }}$ SIL: Squamous intraepithelial lesions.

bLSIL: Low-grade squamous intraepithelial lesions.

${ }^{\mathrm{C}} \mathrm{HSIL}$ : High-grade squamous intraepithelial lesions.

${ }^{\mathrm{d} C}$ : Control - Normal cytology. 
Table 3 MDM2 (rs2278744) polymorphisms in patients with HPV and cervical lesions of low degree (LSIL) and high degree (HSIL) and healthy patients with contraceptive as co-factor

\begin{tabular}{|c|c|c|c|c|c|c|c|c|}
\hline & \multicolumn{3}{|c|}{ Cases } & \multirow{2}{*}{$\begin{array}{c}\text { Normal cytology } \\
\text { Control }^{\mathrm{d}}\end{array}$} & \multicolumn{4}{|c|}{$p$-value; OR [95\% C.I.] } \\
\hline & Total SIL ${ }^{\mathrm{a}}$ & LSIL $^{b}$ & HSIL $^{c}$ & & Total SIL vs. C & LSIL vs. C & HSIL vs. C & HSIL vs. LSIL \\
\hline \multicolumn{9}{|c|}{ SNP309 rs2278744 } \\
\hline \multicolumn{9}{|c|}{ Alelles } \\
\hline $\mathrm{T}$ & $254(0.61)$ & $165(0.63)$ & $89(0.59)$ & $92(0.64)$ & Reference & Reference & Reference & Reference \\
\hline G & $158(0.39)$ & $95(0.37)$ & $63(0.41)$ & $52(0.36)$ & $\begin{array}{c}0.81 ; 1.05 \\
{[0.71-1.54]}\end{array}$ & $\begin{array}{c}0.98 ; 0.99 \\
{[0.66-1.51]}\end{array}$ & $\begin{array}{c}0.68 ; 1.12 \\
{[0.70-1.75]}\end{array}$ & $\begin{array}{c}0.56 ; 1.15 \\
{[0.74-1.75]}\end{array}$ \\
\hline \multicolumn{9}{|c|}{ Genotypes } \\
\hline$\pi$ & $74(0.36)$ & $54(0.41)$ & $20(0.26)$ & $30(0.42)$ & Reference & Reference & Reference & Reference \\
\hline TG & $106(0.51)$ & $57(0.44)$ & $49(0.64)$ & $32(0.44)$ & $\begin{array}{c}0.59 ; 0.74 \\
{[0.42-1.33]}\end{array}$ & $\begin{array}{c}0.99 ; 1.2 \\
{[0.55-1.91]}\end{array}$ & $\begin{array}{c}10.06 ; 2.24 \\
{[1.08-4.63]}\end{array}$ & $\begin{array}{l}{ }^{2} 0.02 ; 2.31 \\
{[1.21-4.41]}\end{array}$ \\
\hline GG & $26(0.13)$ & $19(0.15)$ & $7(0.10)$ & $10(0.14)$ & $\begin{array}{c}0.59 ; 0.95 \\
{[0.41-2.21]}\end{array}$ & $\begin{array}{c}0.99 ; 0.98 \\
{[0.40-2.39]}\end{array}$ & $\begin{array}{c}0.06 ; 1.06 \\
{[0.34-3.25]}\end{array}$ & $\begin{array}{c}0.02 ; 1.07 \\
{[0.39-2.96]}\end{array}$ \\
\hline
\end{tabular}

p-value adjusted with contraceptive.

$p<0.05$ - statistically significant.

${ }^{a}$ SIL: Squamous intraepithelial lesions.

bLSIL: Low-grade squamous intraepithelial lesions.

${ }^{\mathrm{c} H S I L: ~ H i g h-g r a d e ~ s q u a m o u s ~ i n t r a e p i t h e l i a l ~ l e s i o n s . ~}$

${ }^{\mathrm{d} C} \mathrm{C}$ : Control - Normal cytology.

${ }^{1}$ In overdominant model the p-value was $0.019 ; \mathrm{OR}=2.21(95 \% \mathrm{Cl}, 1.13-4.30)$.

${ }^{2}$ In dominant model the p-value was $0.02 ; \mathrm{OR}=2.01(95 \% \mathrm{Cl}, 1.07-3.76)$ and in overdominant model, the $\mathrm{p}$-value was $0.006 ; \mathrm{OR}=2.27(95 \% \mathrm{Cl}, 1.25-4.10)$

would be interesting to examine the reasons for the differences found in this study in greater depth.

When HSIL was compared with LSIL, the difference was significant and showed a risk of 1.81 with the TG genotype when the TT-GG genotype was used as a reference-point (overdominant model). The genetic model suggested by this data appears to be an over-dominant protective effect of MDM2. This model is also called 'heterozygote disadvantage', and although it may appear counterintuitive, a review suggests that this mode of action is perhaps more common than previously thought and cites numerous examples [29]. Indeed, the MDM2 promoter polymorphism has been associated with the severity of HPV, and this also seems to follow a pattern of heterozygote disadvantage.
According to the MDM2 polymorphism (SNP309) analysis, our study reported that there is a small discrepancy between control and LSIL groups. However, this difference is considerable between LSIL and HSIL groups. This suggest that MDM2 SNP309 may be a good marker to assess the progression of LSIL to HSIL. More studies should be done to continue this hypothesis.

We also examined the role of contraceptives as an environmental co-factor in the risk of cervical lesions. Some studies did not observe any association between the use of oral contraceptives and cervical lesions [30-32]. However, several studies demonstrated that when combined with other factors the history of the use of contraceptives affects the development of cervical lesions, and the risk is increased with the duration of their use [33-36]. In our

Table 4 Comparison MDM2 SNP309 allele distribution among oral contraceptive users and non-users between LSIL, HSIL and normal cytology (control)

\begin{tabular}{|c|c|c|c|c|c|c|c|c|c|c|c|c|}
\hline \multirow[b]{2}{*}{ SNP 309 rs2278744 } & \multicolumn{9}{|c|}{ Cases } & \multicolumn{3}{|c|}{ Control $^{d}$} \\
\hline & \multicolumn{3}{|c|}{ Total SIL ${ }^{a}$} & \multicolumn{3}{|c|}{ LSIL $^{b}$} & \multicolumn{3}{|c|}{$\mathrm{HSIL}^{\mathrm{c}}$} & & & \\
\hline Alleles & Yes & No & Total & Yes & No & Total & Yes & No & Total & Yes & No & Total \\
\hline $\mathrm{T}$ & $79(0.58)$ & $175(0.63)$ & $254(0.61)$ & $56(0.57)$ & $109(0.68)$ & $165(0.63)$ & $23(0.60)$ & $66(0.58)$ & $89(0.59)$ & $29(0.60)$ & $63(0.66)$ & $92(0.64)$ \\
\hline G & $57(0.42)$ & $101(0.37)$ & $158(0.39)$ & $42(0.43)$ & $53(0.32)$ & $95(0.37)$ & $15(0.40)$ & $48(0.42)$ & $63(0.41)$ & $19(0.40)$ & $33(0.34)$ & $52(0.36)$ \\
\hline \multicolumn{13}{|l|}{ Genotypes } \\
\hline $\mathrm{TT}$ & $22(0.32)$ & $52(0.38)$ & $74(0.36)$ & $17(0.35)$ & $37(0.46)$ & $54(0.41)$ & $5(0.26)$ & $15(0.27)$ & $20(0.26)$ & $9(0.37)$ & $21(0.44)$ & $30(0.42)$ \\
\hline $\mathrm{TG}$ & $35(0.51)$ & $71(0.51)$ & $106(0.51)$ & $22(0.45)$ & $35(0.43)$ & $57(0.44)$ & $13(0.69)$ & $36(0.63)$ & $49(0.64)$ & $11(0.46)$ & $21(0.44)$ & $32(0.44)$ \\
\hline GG & $11(0.17)$ & $15(0.11)$ & $26(0.13)$ & $10(0.20)$ & $9(0.11)$ & $19(0.15)$ & $1(0.05)$ & $6(0.10)$ & $7(0.10)$ & $4(0.17)$ & $6(0.12)$ & $10(0.14)$ \\
\hline
\end{tabular}

${ }^{a}$ SIL: Squamous intraepithelial lesions.

bLSIL: Low-grade squamous intraepithelial lesions.

${ }^{\mathrm{C}} \mathrm{HSIL}$ : High-grade squamous intraepithelial lesions.

${ }^{\mathrm{d} C o n t r o l: ~ N o r m a l ~ c y t o l o g y . ~}$ 
study, the use of contraceptives was either evaluated alone or together with MDM2 SNP309 in women with HPV infection. No association was found when the use of contraceptives was evaluated alone. This finding was consistent with the results of Castle et al. [32], who did not find a higher risk of high-grade lesions or cervical cancer among 1160 women who used contraceptives compared with 2094 who did not use them. Hildesheim et al. [31] did not find oral contraceptives had an effect on cervical lesions when this co-factor was evaluated alone. Deacon et al. [30] observed that the use of oral contraceptives was not significantly associated with high-grade lesions. When comparing 211 HSIL and 1475 invasive cancer patients with $255 \mathrm{HPV}$ - positive controls without lesions, Moreno et al. [35] found that those who had used contraceptives for less than 5 years did not demonstrate an increased risk of cervical cancer. Nevertheless, the risk increased 2.82- fold when the use was over a period of 5-9 years and 4.03- fold when the use lasted for 10 years or more. Brisson et al. [34] observed a relative 1.9 risk of high-grade lesions in patients that had used contraceptives for 6 years or more compared with those who never used them. Briton et al. [33], found that the risk was two-fold for users of 5 or more years. A study conducted by Luhn et al. [36] with 2783 women in various stages of cervical disease, showed that long-term oral contraceptive use (a period of more than 10 years) was associated with HSIL with the risk being 2.42- fold higher than those that had never used contraceptives.

These results are in contrast with the current study where the use of contraceptives alone was not associated with development of cervical lesions. Factors such as the discontinuous use of contraceptives and the duration of their use can explain this divergence. It is also possible that in studies where associations were found between the use of contraceptives and development of lesions and cervical cancer, there is also an interaction with the host genetic factors which were not analyzed.

When the use of contraceptives was examined with the presence of MDM2 SNP309 in the development of cervical lesions, a risk of 2.21 was found in patients with HSIL and TG genotype when compared with control and MDM2 MDM2 SNP309. When HSIL was compared with LSIL, the risk was 2.31 (codominant model), 2.01 (dominant model) and 2.27 (overdominant model). These results provide clues that contraceptives can act synergistically by increasing susceptibility to the development of high-grade cervical lesions. According to Bond and Levine

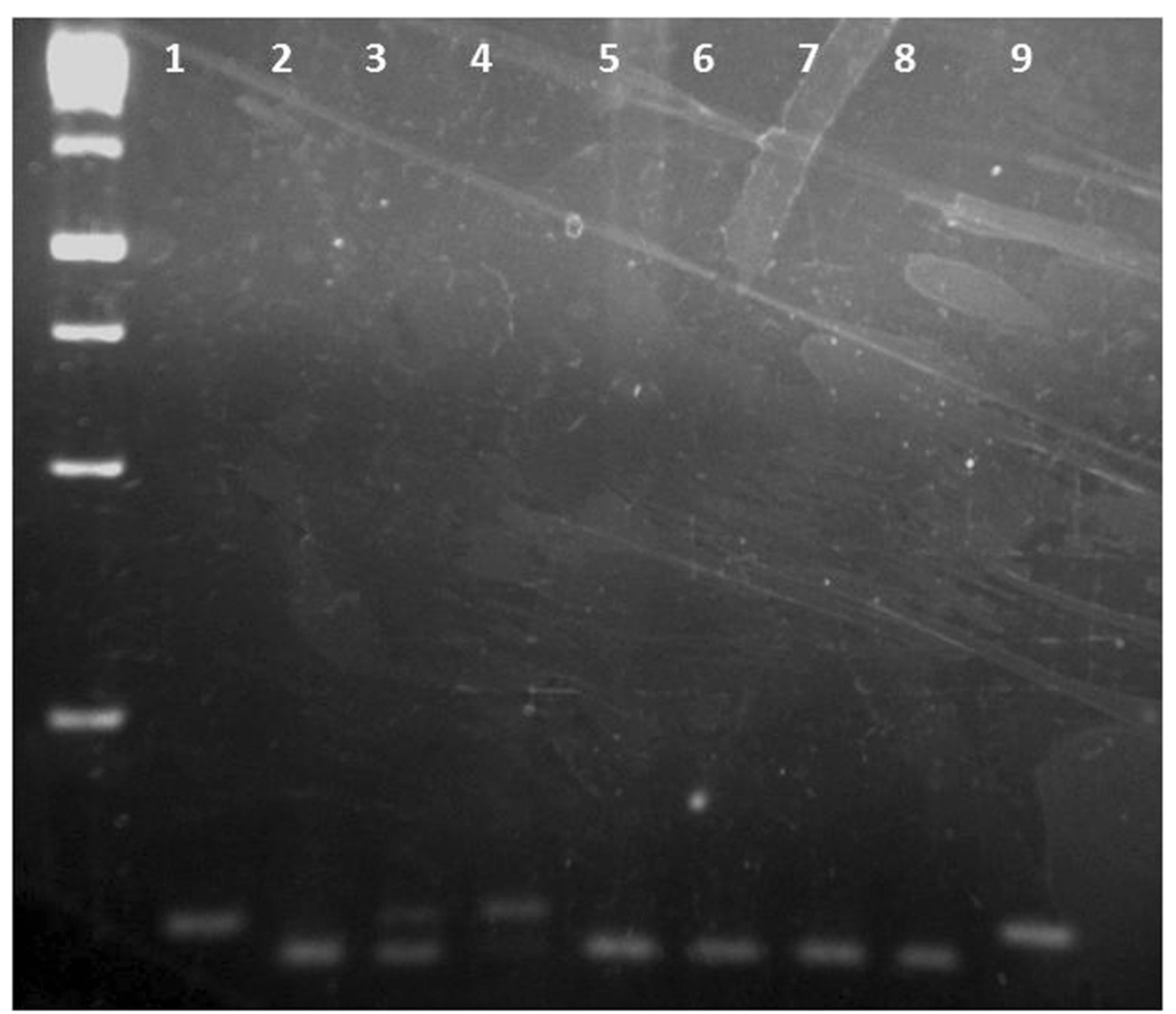

Figure 1 Representative genotypes of MDM2 SNP (rs2278744). MDM2 SNP (rs2278744) - Wild-type homozygous $\pi$ produced a single 121 bp fragment (Columns 1,9), homozygous GG produced 2 fragments of $104 \mathrm{bp}$ and $17 \mathrm{bp}$, which was not detected on the gel (Colunms 2,5,6,7,8) and heterozygot TG produced 3 fragments of $121 \mathrm{bp}, 104 \mathrm{bp}$ and $17 \mathrm{bp}$ (Colunms 3,4). 
[37], when the estrogen signaling pathway is activated in the presence of SNP309, the basal levels of the MDM2 in the cell are elevated, due to the affinity binding site of the transcription factor Sp1 created in the promoter region. As a result, the levels of p53 are reduced and the carriers of the $\mathrm{G}$ allele have a low cellular stress response. Thus, the activated estrogen signaling pathway is necessary for the $\mathrm{G}$ allele to accelerate the formation the tumor [37].

This is the first study that showed an association between the use of contraceptives and MDM2 SNP309 (rs2278744) in the development of cervical lesions of women HPV infected. The findings corroborate the hypothesis that the use of contraceptives may be a co-factor together with HPV infection and MDM2 polymorphism in the development of cervical lesions.

These findings reported that MDM2 SNP309 (rs2278744) were significantly associated with women HPV infected that using oral contraceptive, suggesting that contraceptives act together with MDM2 SNP309 (rs2278744) and HPV infection in the development of cervical lesions in women HPV infection. Additional studies should be conducted in order to prove that the polymorphism in MDM2 gene may come to be used as a marker of the evolution of high grade lesions in women HPV infected.

\section{Methods}

Ethics statement

The study was approved by the "Research Ethics Committee of University of Pernambuco", Brazil, (HUOC/ PROCAPE 64/2010) and was approved by the institutional review board of the University Hospital Oswaldo Cruz. All patients provided written informed consent prior to collection of sample. It was obtained informed written consent from the next of kin, caretakers, or guardians on behalf of the minors that were enrolled in this study.

\section{Studied subjects}

The cervical smears were obtained from 287 patients from North-East Brazil who volunteered to take part in cervical cancer screening. All the samples included in this study were HPV positive. The control group consisted of 75 patients without cervical lesions and the case group consisted of 212 patients with cervical lesions which was divided into LSIL (130 - Low grade squamous intraepithelial lesions) and HSIL (82 - High grade squamous intraepithelial lesions). The patients signed a consent form that was approved by the ethics committee of the university (HUOC/PROCAPE 64/2010).
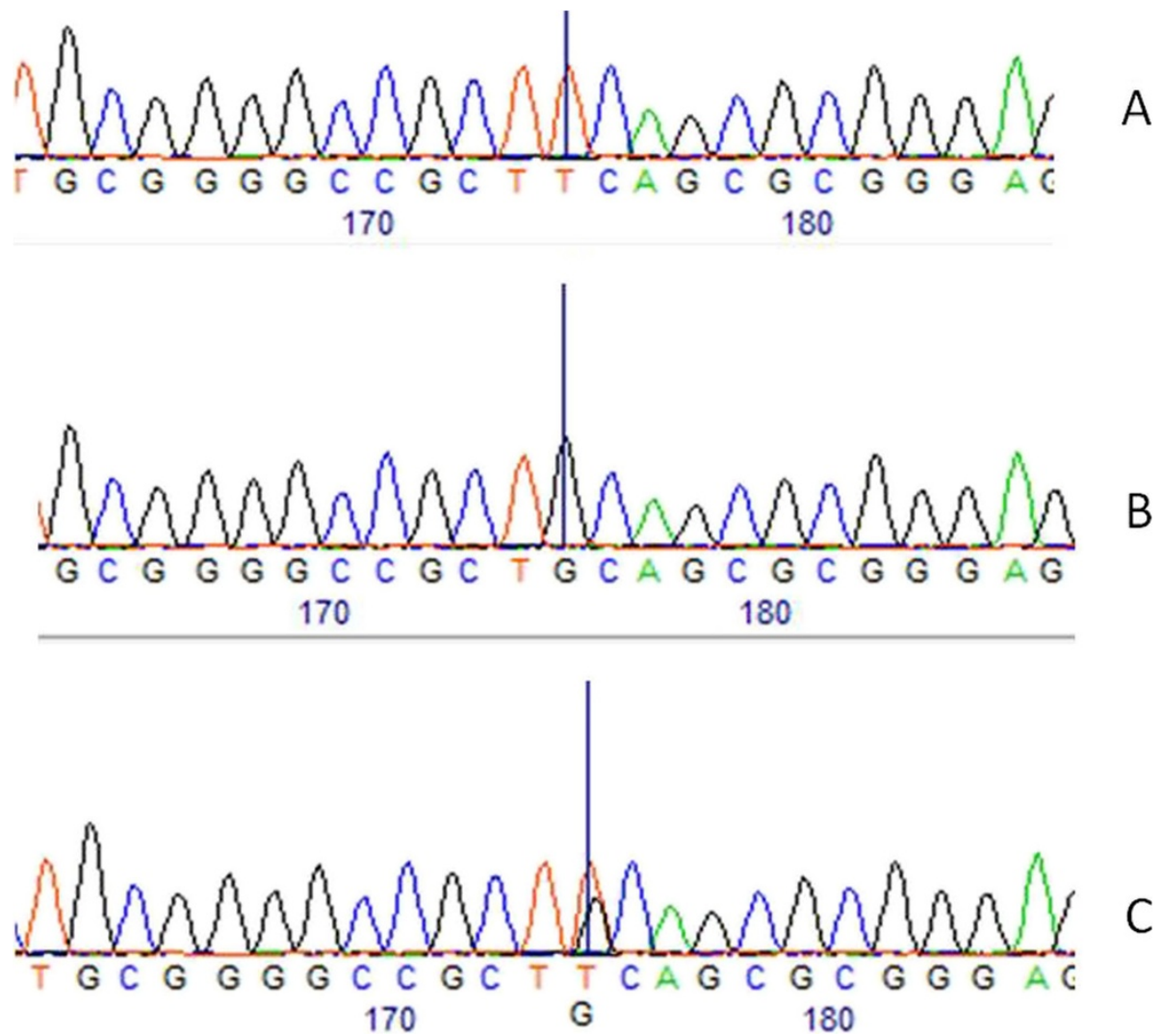

Figure 2 Sequence analysis. Comparisons of the three genotypes on the site of nucleotide change. $\mathbf{A}$ - Wild-type homozygous TT. B - Homozigous GG. C - Heterozygous TG. 


\section{Preparation of samples and DNA extraction}

After being collected, the samples were placed in polyethylene tubes containing phosphate-buffered saline and stored at $-20^{\circ} \mathrm{C}$ for further processing. DNA was extracted using the DNeasy Blood and Tissue Kit (Qiagen, São Paulo/Brazil) in accordance with the manufacturer's instructions.

\section{HPV detection}

PCR was used for HPV DNA detection and involved the amplification of the viral L1 gene fragment using degenerated primers (MY09/MY11) [38,39]. The primer sequences were MY09- CGTCCMARRGGAWACTGATC and MY11- GCMCAGGGWCATAAYAATGG.

\section{MDM2 SNP (rs2279744) genotyping}

A Primer- Introduced Restriction Analysis PCR (PIRA$\mathrm{PCR}$ ) assay was used for the genotyping of MDM2 SNP309. This method is based on sense and antisenseprimers, where there is a mismatch of the nucleotide close to a polymorphic site, which is introduced to create a restriction site. The antisense-primer introduced A to replace $\mathrm{G}$ at $2 \mathrm{bp}$ from the polymorphic site to create a PstI restriction site. The primer sequences were 5'-GATTTCGGACGGCTCTCGCGGC-3' (sense) and 5'-CATCCGGACCTCCCGCGCTG-3' (antisense) [40]. $50 \mathrm{ng}$ of the DNA template from each sample was amplified with $0.1 \mathrm{mM}$ dNTP, $1 \mathrm{X}$ Taq reaction buffer, $1 \mathrm{mM} \mathrm{MgCl} 2,0.8 \mu \mathrm{M}$ of each primer and $1 \mathrm{U}$ Taq DNA polymerase in a final volume of $25 \mu \mathrm{L}$. The amplification reaction was carried out under the following conditions: $95^{\circ} \mathrm{C}$ for 5 minutes for the initial denaturation of the genomic material, 35 cycles of $95^{\circ} \mathrm{C}$ for 30 seconds (denaturation), $66.5^{\circ} \mathrm{C}$ for 40 seconds (annealing), $72^{\circ} \mathrm{C}$ for 45 seconds (extension) for the amplification of the gene segment of interest and a cycle of $72^{\circ} \mathrm{C}$ for 10 minutes in the final extension of the fragment. The $121 \mathrm{bp}$ PCR fragment was then digested for 16 hours by $5 \mathrm{U}$ PstI (Invitrogen, São Paulo/Brazil). The wild-type T allele produced a single $121 \mathrm{bp}$ fragment and the polymorphic G allele produced two fragments of 104- and $17 \mathrm{bp}$. The product was analyzed on $2 \%$ agarose gel stained with ethidium bromide (Figure 1). The nucleotide change and the three genotypes can be visualized on sequences analysis that were shown on Figure 2.

\section{Statistical methods}

The genetic frequency and association analysis between the comparison groups was performed with UNPHASED v.3.121 [41], whereas association analysis between these groups and risk factor (use of contraceptive) was conducted with SNPStats [42]. All the tests were two-tailed and the level of significance for all of the statistical results was set at $\mathrm{p}<0.05$.

\section{Ethical approval}

This work has been approved by Ethics Committee on Human Research - Hospital Complex HUOC/PROCAPE (HUOC/PROCAPE 64/2010).

\section{Competing interest}

The authors have no conflict of interest to declare.

\section{Authors' contributions}

The individual contribution of each author was performed as follows: CMMA performed all the experimental work and manuscript elaboration; KC, APADG, BSC and RCPL performed experimental support; MVC and SSLPJ performed the statistical analyzes; ACF, was responsible for orientation and coordination of this manuscript; MTCM; JCSN; LAFS and VQB, were the consultants of this manuscript. All authors read and approved the final manuscript.

\section{Acknowledgments}

We would like to thank the Brazilian Institutes FACEPE and CAPES for providing a Research Fellowship for C.M.M.A, B.S.C. and an A.P.A.D.G. Doctoral Degree, respectively.

\section{Author details}

'Laboratory of Molecular Studies and Experimental Therapy, Department of Genetics, Universidade Federal de Pernambuco, Pernambuco, Brazil. ${ }^{2}$ Department of Biology, Faculty of Medicine, Masaryk University, Brno, Czech Republic. ${ }^{3}$ Laboratory of Human Molecular Genetics, Department of Genetics, Universidade Federal de Pernambuco, Pernambuco, Brazil. ${ }^{4}$ Molecular and Cytological Research Laboratory, Department of Histology, Universidade Federal de Pernambuco, Pernambuco, Brazil. ${ }^{5}$ Institute of Biological Sciences and Health, Federal University of Alagoas, Alagoas, Brazil. 'Laboratory of Molecular Biology of Center of Pediatric Oncohaematological, University of Pernambuco, Pernambuco, Brazil.

Received: 2 February 2014 Accepted: 16 June 2014

Published: 18 July 2014

\section{References}

1. Jemal ADVM, Bray F, Center MM, Ferley J, Ward E, Forman D: Global cancer statistic. CA Cancer J Clin 2011, 61:69-90.

2. INCA- Instituto Nacional do Câncer Brasil José Alencar Gomes da Silva: Estimativa 2012: Incidência de Câncer no Brasil. Coordenação Geral de Ações Estratégicas, Coordenação de Prevenção e Vigilância. Rio de Janeiro. 2011. [Accessed January 30, 2013] Available at: http://portal.saude.sp.gov.br/ resources/ses/perfil/gestor/homepage/estimativas-de-incidencia-de-cancer2012/estimativas_incidencia_cancer_2012.pdf.

3. Ince $U$, Aydin O, Peker O: Clinical importance of "low-grade squamous intraepithelial lesion, cannot exclude high-grade squamous intraepithelial lesion (LSIL-H)" terminology for cervical smears 5-year analysis of the positive predictive value of LSIL-H compared with ASC-H, LSIL, and HSIL in the detection of high-grade cervical lesions with a review of the literature. Gynecol Oncol 2011, 121:152-156.

4. Richart RM, Barron BA: A follow-up study of patients with cervical dysplasia. Am J Obstet Gynecol 1969, 105:386-393.

5. Zur Hausen H: Papillomavirus infections - a major cause of human cancers. Biochim Biophys Acta 1996, 1288(2):F55-F78.

6. Bray F, Carstensen B, Moller H, Zapa M, Zakelji MP, Lawrence G, Hakama M, Weiderpass E: Incidence trends of adenocarcinoma of the cervix in 13 European countries. Cancer Epidemiol Biomarkers Prev 2005, 14(9):2191-2199.

7. Hemminki $K$, Chen B: Familial risks for cervical tumors in full and half siblings: etiologic apportioning. Cancer Epidemiol Biomarkers Prev 2006, 15(7):1413-1414.

8. Vink JM, Emenade FJ VK, Meijer CJLM, Casparie MK, Meijer GA, Boomsma DI: Cervix smear abnormalities: linking pathology data in female twins, their mothers and sisters. Eur J Hum Genet 2011, 19(1):108-111.

9. Freitas AC, Gurgel APAD, Chagas BS, Coimbra EC, Amaral CMM: Susceptibility to cervical cancer: an overview. Gynecol Oncol 2012, 126(2):304-311.

10. Moodley M, Moodley J, Chetty R, Herrington CS: The role of steroid contraceptive hormones in the pathogenesis of invasive cervical cancer: a review. Intern I gynecol cancer 2003, 13:103-110. 
11. Gadducci A, Barsotti C, Cosio S, Domenici L, Genazzani AR: Smoking habit, immune suppression, oral contraceptive use, and hormone replacement therapy use of cervical carcinogenesis: a review of literature. Gynecol endoc 2011, 27(8):597-604.

12. Ghanem KG, Datta SD, Unger ER, Hagensee M, Shlay JC, Kerdnt P, Hsu K, Koutsky LA: The association of current hormonal contraceptive use with type-specific HPV detection. Sex transm infect 2011, 87:385-388.

13. Vessey $M$, Yeates $D$ : Oral contraceptive use and cancer: final report from the oxford-family planning association contraceptive study. Contraception 2013, 88:678-683.

14. Urban M, Banks E, Egger S, Canfell K, O'Connell D, Beral V, Sitas F: Injectable and oral contraceptive use and cancers of the breast, cervix, ovary, and endometrium in black South African women: case-control study. Plos med 2012, 9(3):1-8.

15. Talis AE, Huibregtse JM, Howley PM: The role of E6AP in the regulation of 553 protein levels in human papillomavirus (HPV)-positive and HPV-negative cells. J Bio/ Chem 1998, 273(11):6439-6445.

16. Wade M, Wang YV, Wahl GM: The p53 orchestra: Mdm2 and Mdmx set the tone. Trends Cell Biol 2010, 20(5):299-309.

17. Momand J, Zambetti GP, Olson DC, George D, Levine AJ: The mdm-2 oncogene product forms a complex with the $\mathrm{p} 53$ protein and inhibits p53-mediated transactivation. Cell 1992, 69(7):1237-1245.

18. Chen X, Sturgis EM, Lei D, Dahlstrom K, Wei Q, Li G: Human papillomavirus seropositivity synergizes with MDM2 variants to increase the risk of oral squamous cell carcinoma. Cancer Res 2010, 70:7199-7208.

19. Hav M, Libbrecht L, Ferdinande L, Pattyn P, Laurent S, Peeters M, Pract M, Paulwels P: MDM2 gene amplification and protein expressions in colon carcinoma: is targeting MDM2 a new therapeutic option? Virchows Arch 2011, 458(2):197-203.

20. Dong J, Ren B, Hu Z, Chen J, Hu L, Dai J, Jin G, Xu L, Shen H: MDM2 SNP309 contributes to non-small cell lung cancer survival in Chinese. Mol Carcinog 2011, 50(6):433-438

21. Joshi AM, Budhathoki S, Ohnaka K, Mibu R, Tanaka M, Kakeji Y, Maehara Y, Okamura T, Ikejiri K, Futami K, Maekawa T, Yasunami Y: TP53 R72P and MDM2 SNP309 polymorphisms and colorectal cancer risk: the Fukuoka colorectal cancer study. Jpn J Clin Oncol 2011, 41(2):232-238.

22. Hirata H, Hinoda Y, Kikuno N, Kawamoto K, Suehiro Y, Tanaka Y, Dahiya R: MDM2 SNP309 polymorphism as risk factor for susceptibility and poor prognosis in renal cell carcinoma. Clin Cancer Res 2007, 13(14):4123-4129.

23. Bond GL, Hu W, Bond EE, Robins H, Lutzker SG, Arva NC, Bargonetti J, Bartel F, Taubert H, Wuerl P, Onel K, Yip L, Hwang SJ, Strong LC, Lozano G, Levine AJ: A single nucleotide polymorphism in the MDM2 promoter attenuates the p53 tumor suppressor pathway and accelerates tumor formation in humans. Cell 2004, 119(5):591-602.

24. Meissner RV, Barbosa RNF, Fernandes JV, Galvão TM, Galvão AFO, Oliveira GHM: No association between SNP309 promoter polymorphism in the MDM2 and cervical cancer in a study from Northeastern Brazil. Cancer Detect and Prev 2007, 31:371-374

25. Singhal P, Hussain S, Thakur N, Batra S, Salhan S, Bhambani S, Bharadwaj: Association of MDM2 and p53 polymorphisms with the advancement of cervical carcinoma. DNA Cell Biol 2013, 32(1):19-27.

26. Jiang $P$, Li W, Zeng $X$, Nie L, Tang J: The role of TP53 and MDM2 polymorphisms in the risk of cervical cancer. Adv Sci Lett 2012. 10(1):349-352 (4).

27. Nunobiki O, Ueda M, Yamamoto M, Toji E, Sato N, Izuma S, Okamoto Y, Torii K, Noda S: MDM2 SNP309 human papillomavirus infection in cervical carcinogenesis. Gynecol Oncol 2010, 118:258-261.

28. Wo X, Han D, Sun H, Liu Y, Meng X, Bai J, Chen F, Yu Y, Jin Y, Fu S: MDM2 SNP309 contributes to tumor susceptibility: a meta-analysis. J Genet Genomics 2011, 78:341-350.

29. Magouri K, Gould F: Genetically engineered underdominance for manipulation of pest populations: a deterministic model. Genet 2006, 172:2613-2620.

30. Deacon JM, Evans CD, Yule R, Desai M, Binns W, Taylor C, Peto J: Sexual behavior and smoking as determinants of cervical HPV infection and of CIN3 among those infected: a case-control study nested within the Manchester cohort. Br J Cancer 2000, 88(11):1565-1572.

31. Hildesheim A, Herrero R, Castle PE, Wacholder S, Bratti MC, Sherman ME, Lorincz AT, Burk RD, Morales D, Rodriguez AC, Helgen K, Alfro M, Hutchinson M, Balmaceda I, Greenberg M, Schiffman M: HPV co-factors related to the development of cervical cancer: results form a population-based study in Costa Rica. Br J Cancer 2001, 84(4):1219-1226.

32. Castle PE, Wacholder S, Lorincz AT, Scott DR, Sherman ME, Glass AG, Rush $B B$, Schussler JE, Schiffman M: A prospective study of high-grade cervical neoplasia risk among human papillomavirus-infected women. $J$ Natl Cancer Inst 2002, 94(18):1406-1414.

33. Brinton LA: Oral contraceptives and cervical neoplasia. Contraception 1991, 43(6):581-595.

34. Brisson J, Morin C, Fortier M, Roy M, Bouchard C, Leclerc J, Christen A, Guimont C, Penault F, Meisels A: Risk factors for cervical intraepithelial neoplasia: differences between low- and high-grade lesions. Am $J$ Epidemio/ 1994, 140(8):700-710

35. Moreno V, Bosch FX, Muñoz N, Meijer CJLM, Shah KV, Walboomers JMM, Herrero R, Franceschi S: Effect of oral contraceptives on risk of cervical cancer in women with human papillomavirus infection: the IARC multicentric casecontrol study. The Lancet 2002, 359:1085-1092.

36. Luhn P, Walker J, Schiffman M, Zuna RE, Dunn TS, Gold MA, Smith K, Mathews C, Allen RA, Zhang R, Wang S, Wentzensen N: The role of co-factors in the progression from human papillomavirus infection to cervical cancer. Gynecol Oncol 2013, 128(2):265-270.

37. Bond $G L$, Levine AJ: A single nucleotide polymorphism in the $p 53$ pathway interacts with gender, environmental stresses and tumor genetics to influence cancer in humans. Oncogene 2007, 26:1317-1323.

38. Manos MM, Ting Y, Wright DK, Lewis AJ, Broker TR, Wolinsky SM: Use of polymerase chain reaction amplification for the detection of genital human papillomavirus. Cancer Cells 1989, 7:209-214.

39. Karlsen F, Kalantari M, Jenkins A, Pettersen E, Kristensen G, Holm R, Johansson B, Hagmar B: Use of multiple PCR primer sets for optimal detection of human papillomavirus. J Clin Microbiol 1996, 34(9):2095-2100.

40. Ma H, Jin G, Hu Z, Zhai X, Wang S, Wang X, Qin J, Jin G, Liu J, Wang X, Wei $\mathrm{Q}$, Shen $\mathrm{H}$ : Polymorphisms in the MDM2 promoter and risk of breast cancer: a case-control analysis in a Chinese population. Cancer Lett 2006, 240(2):261-267.

41. Dudbridge F: Likelihood-based association analysis for nuclear families and unrelated subjects with missing genotype data. Hum Hered 2008 66:87-98.

42. Sole X, Guino E, Valls J, Iniesta R, Moreno V: SNPStats: a web tool for the analysis of association studies. Bioinformatics 2006, 22(15):1928-1929.

doi:10.1186/1750-9378-9-24

Cite this article as: Amaral et al:: MDM2 polymorphism associated with the development of cervical lesions in women infected with Human papillomavirus and using of oral contraceptives. Infectious Agents and Cancer 2014 9:24.

\section{Submit your next manuscript to BioMed Central and take full advantage of:}

- Convenient online submission

- Thorough peer review

- No space constraints or color figure charges

- Immediate publication on acceptance

- Inclusion in PubMed, CAS, Scopus and Google Scholar

- Research which is freely available for redistribution 